\section{Speak to the customer success team}

Dentally will be on stand H72 at the BDIA Dental Showcase, 17-19 October at the NEC, Birmingham. It is a great opportunity for dentists to see for themselves why Dentally is trusted by over 5,000 dental professionals both in the UK and abroad.

Dentally's customer success team will also be on hand throughout the show to talk to existing customers about some of their latest and exciting new product developments.

The team at Dentally understand that running a successful dental practice takes time, and with Dentally there are no more software updates and no lengthy IT admin. Dental practitioners can run faster reports, enjoy efficient charting and all the benefits of simple patient management. So, they get more time doing what they love: helping patients and not sitting in front of a computer.

Dentally will also be showcasing its partnership with Planmeca, the world's leading manufacturer of low dose digital imaging equipment. So why not take advantage of the partnership and talk to Dentally's team about the best tools for your practice for both 3D and 2D imaging equipment?

Don't forget to look out for Dentally's exciting integrations with other platforms, including an integration with DenGro, a marketing lead management tool tailored for dental practices.

For more information about practice management software that saves you time or to arrange a demo visit https://dentally. co or email hello@dentally.co to talk to Dentally's friendly team.

\title{
Symptomatic relief of xerostomia
}

Xerostomia, or dry mouth, can cause patients discomfort and lead to problems with eating and talking. It can also leave them more prone to caries.

For symptomatic relief of xerostomia (once serious causes have been eliminated) the dental practitioner will be able to recommend various solutions, such as ensuring the patient stays hydrated.

For their daily cleaning, TANDEX fits the bill perfectly. From high-quality brushes to the FLEXI interdental and the SOLO interspace brush, to an alcohol-free mouth rinse, TANDEX has everything to clean the mouth gently, yet effectively.

For the full product list, contact the friendly TANDEX team. For more information on Tandex's range of products, visit www.tandex.dk.
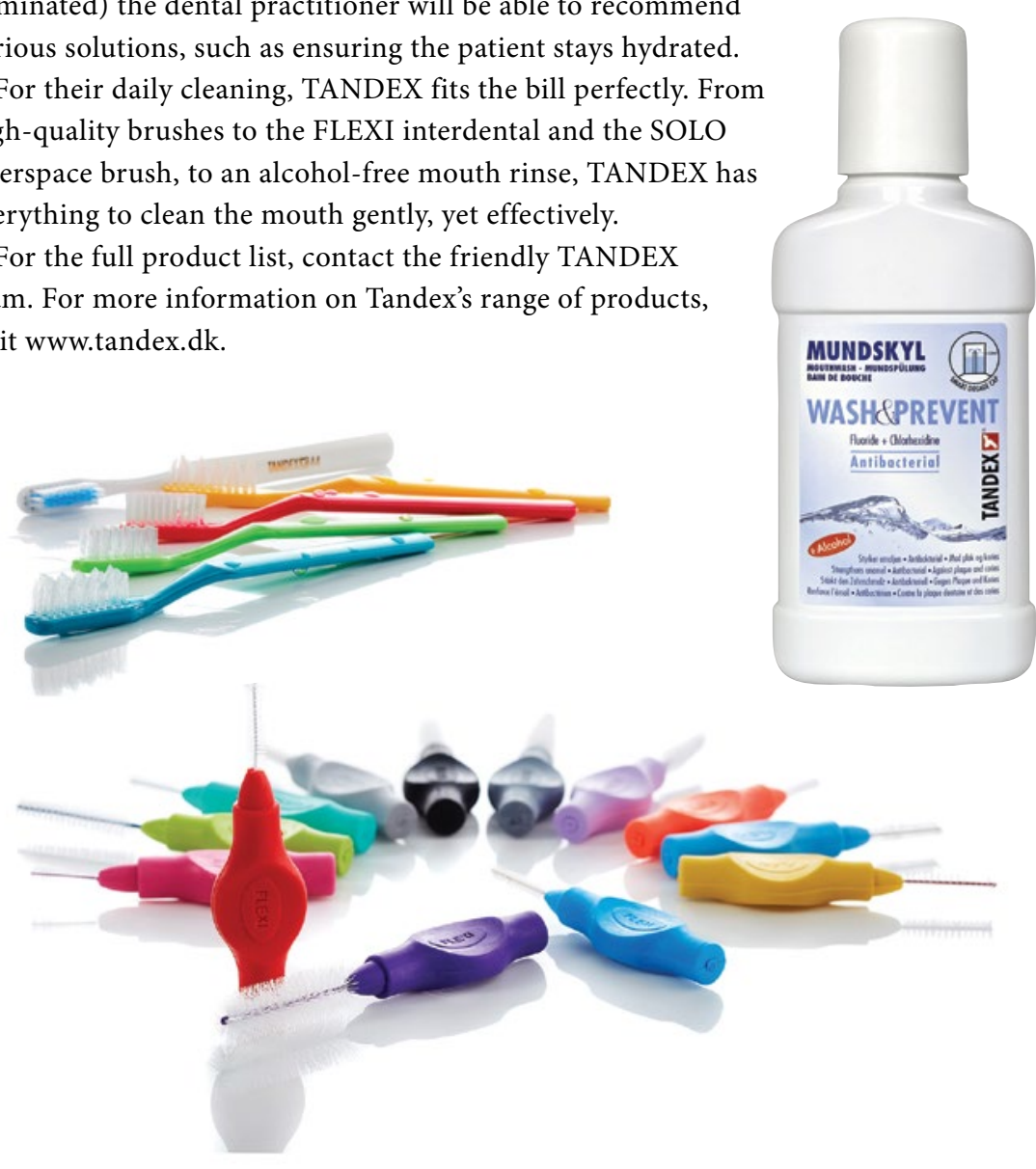